\title{
Efficacy of nedocromil 2\% versus fluorometholone $0.1 \%$ : a randomised, double masked trial comparing the effects on severe vernal keratoconjunctivitis
}

\author{
Khalid F Tabbara, Soliman A Al-Kharashi
}

\begin{abstract}
Aims-To compare the efficacy of topical nedocromil $2 \%$ with fluorometholone $0.1 \%$ in vernal keratoconjunctivitis (VKC).

Methods-In a double masked random design, 24 patients with severe vernal keratoconjunctivitis were placed at random on nedocromil $2 \%$ eye drops in one eye and fluorometholone $0.1 \%$ in the fellow eye. At the end of the 2 week treatment period, the patient crossed over the eye drops (if asymptomatic in one eye), or continued with nedocromil sodium in both eyes (if asymptomatic in both eyes). All patients were examined weekly and ocular surface temperature recorded for a period of 6 weeks.

Results-Improvement in the watering, discharge, conjunctival hyperaemia, papillary hypertrophy, and Trantas' dots was noted in both groups, but overall fluorometholone was significantly more effective than nedocromil. Eyes treated with fluorometholone showed a significant decrease in ocular surface temperature compared with nedocromil treated eyes $(\mathbf{p}=0.03)$.
\end{abstract}

Conclusions-Both nedocromilandfluorometholone were effective in ameliorating the signs and symptoms of vernal keratoconjunctivitis. No adverse effects were noted in the nedocromil group.

(Br f Ophthalmol 1999;83:180-184)

Vernal keratoconjunctivitis (VKC) is an allergic condition which predominantly affects male children and young adults. VKC victims may suffer from symptoms throughout the year, but the intensity of signs and symptoms increases during the hot seasons. VKC is a form of allergic conjunctivitis representing a complex immunopathogenic mechanisms characterised by a cascade of events leading to the release of chemotactic, vasoactive, and nerve stimulating mediators. ${ }^{1}$

During the allergic process, there is enhanced expression of cell surface adhesion molecules both on the vascular endothelial cells and on the circulating leucocytes. ${ }^{2}$ Furthermore, elevated IgE levels are noted in tears of patients with allergic conjunctivitis. ${ }^{34}$ Immunohistochemical studies of conjunctival biopsy specimens obtained from patients with VKC have shown the presence of a number of inflammatory cells including lymphocytes, mast cells, eosinophils, and basophils.

Mast cells appear to play a pivotal role in the pathogenesis of VKC. Mast cells have been subdivided into two types according to their neutral protease composition, $\mathrm{T}$ lymphocyte dependency, and ultrastructural characteristics. ${ }^{5-8}$ Mast cells containing tryptase but no chymase are known as $\mathrm{MC}_{\mathrm{T}}$, and mast cells containing both tryptase and chymase are known as $\mathrm{MC}_{\mathrm{TC}}$.

While mast cells are not found in conjunctival epithelium in normal subjects, in those with VKC there is a marked increase in their numbers. ${ }^{9}$

An increase in the level of interleukin 2 (IL-2) receptors has been shown in patients with allergic conditions such as asthma. CD4+ $\mathrm{T}$ lymphocytes are involved in the pathogenesis of vernal keratoconjunctivitis. ${ }^{10} \mathrm{CD} 4+$ cells are an important source of IL-5 and IL-3 and GM-CSF. These cytokines help in the differentiation, maturation, and activation of eosinophils. The cytokines are also secreted by mast cells, macrophages, epithelial cells, fibroblasts, and neutrophils. CD4+ $\mathrm{T}$ cell recruitment results in an intense inflammatory reaction of the conjunctiva. In conjunctival biopsy specimens obtained from patients with VKC, there was a statistically significant decrease in the number of class II antigen positive cells in the epithelium and stroma of conjunctival biopsy specimens after cyclosporine treatment. ${ }^{10}$ The number of mast cells was not altered by treatment with topical cyclosporine. ${ }^{10} \mathrm{~A}$ clinical improvement in VKC after topical cyclosporine therapy may result from the immunomodulating effect on the components of cell mediated and humoral immune responses which may affect the mast cell functions without altering the number of mast cells. $^{11}$

Eosinophil also plays a significant role in the pathogenesis of VKC. Eosinophils are increased in the conjunctiva of patients with VKC. Their granules contain eosinophil cationic protein, eosinophil peroxidase, eosinophil derived neurotoxin, major basic protein (MBP), collagenase, elastase, and CharcotLeyden crystal protein. ${ }^{12}{ }^{13}$

A series of sequential events occurs in the conjunctival mast cells of patients with VKC resulting in the release of inflammatory mediators. Several agents, such as disodium cromoglycate, have been designed to interfere with the release of the mast cell mediators. Although
Accepted for publication 26 August 1998 
topical steroids are effective in VKC, these agents carry considerable risk of complications such as glaucoma, cataract, and predisposition to ocular surface infections. Nedocromil sodium has been shown to interfere with mast cell degranulation and appears to be more effective than disodium cromoglycate in vitro. ${ }^{14-16}$ Nedocromil sodium has been developed for the treatment of allergic eye disease. Several placebo controlled clinical trials have demonstrated the effectiveness of nedocromil sodium $2 \%$ eye drops in the treatment of seasonal allergic conjunctivitis. ${ }^{17-19}$ Other studies have compared nedocromil sodium $2 \%$ eye drops with disodium cromoglycate $2 \%$ and $4 \%$ eye drops. ${ }^{20-22}$ It was shown that nedocromil sodium $2 \%$ eye drops were as effective as disodium cromoglycate $2 \%$ eye drops. ${ }^{21}$ Some patients with severe VKC do not respond to topical disodium cromoglycate alone and may require topical steroid therapy.

We decided to compare the safety and efficacy of nedocromil sodium $2 \%$ eye drops with fluorometholone $0.1 \%$ eye drops in patients with severe bilateral VKC (limbal and conjunctival). In a double masked, crossover, randomised study, nedocromil was given to one eye and fluorometholone to the fellow eye of the same patient.

\section{Patients and methods}

We included 24 patients (21 males and three females) with VKC with limbal and conjunctival involvement. Their mean age was 10.63 years with a range of 5-21 years (SD 4.23). Each patient was treated with nedocromil in one eye and fluorometholone in the other eye. The diagnosis of VKC was made based on history of symptoms (redness, itching, tearing, etc) and signs of conjunctival papillary hypertrophy and hyperaemia, gelatinous infiltration of the limbus, Trantas' dots, and superficial punctate keratitis. Inclusion criteria included patients with bilateral severe VKC (grade 3 symptoms and signs: see grading) who had not received any VKC targeted therapy for a period of 2 weeks before study enrolment. Informed consent was obtained from the patient or his/her guardian. Exclusion criteria applied to all patients who were pregnant or lactating, and patients who had significant concomitant disease or who were taking systemic or topical medications. Contact lens wearers or patients with ocular disorders such as glaucoma, blepharitis, or uveitis as well as those enrolled but not complying with the dosing schedule were also excluded.

In a double masked random paired design, patients underwent complete ophthalmological examination. A study controller was assigned to monitor therapy group assignment and therapy group crossover. Each patient was given nedocromil $2 \%$ (one eye drop four times daily) to one eye at random, and fluorometholone $0.1 \%$ (one eye drop four times daily) to the other eye. Each patient was admitted to the hospital and treatment was administered by the nursing staff for a period of 1 week. At the end of 1 week, the patient was given the two types of medications (A and B) with a red or blue label and instructions were given to the parents or relatives to maintain the dosing schedule and instil each of the colour coded eye drops concurrently into the designated eye. At the conclusion of the 2 week treatment period, patients were evaluated and the findings analysed. Patients who were asymptomatic in one eye at the end of the 2 week treatment period were instructed to cross over the medications so that the eye previously treated with medication $\mathrm{A}$ would then receive medication $\mathrm{B}$, and vice versa. They were asked to continue the therapy for another period of 2 weeks.

\section{Clinical evaluation and grading of symptoms and signs}

\section{EXAMINATION}

A medical history was obtained and all medications taken at or before the time of evaluation were documented. Demographic data, details of eye examination, and clinical findings were recorded. The clinicians (both authors) enrolling the patient conducted all subsequent examinations and follow ups. In their evaluation of patients, both authors were in agreement with the grading system described here. All patients had a severe form of VKC defined as grade 3 in signs and symptoms.

\section{GRADING OF SYMPTOMS}

The major symptoms of VKC including itching, watering, grittiness, photophobia, burning sensation, and discharge were recorded separately and graded. We applied grade 0 for no symptoms, grade 1 for mild symptoms, grade 2 for moderate symptoms, and grade 3 for severe symptoms. (Grades 2 and 3 usually disrupted the patient's daily activities.)

\section{GRADING OF SIGNS}

The following signs were assessed: hyperaemia, papillary hypertrophy, punctate keratitis and Trantas' dots. Hyperaemia and papillary hypertrophy were graded as follows: $0=$ none, $1=$ mild, $2=$ moderate, $3=$ severe. Punctate keratitis was graded as follows: $0=$ none, $1=1$ quadrant affected, $2=2$ quadrants affected, 3 $=3$ or more quadrants affected. Trantas' dots were graded as follows: $0=$ none, $1=1$ or 2 dots, $2=3$ or 4 dots, $3=$ more than 4 dots.

The authors/examiners were observer blind at assessment time and at therapy crossover point. At the conclusion of the study, both patient and investigator were asked to nominate their preferred mode of therapy - that is, medication A, B, or no preference.

\section{OCULAR SURFACE TEMPERATURE}

The ocular surface temperature was measured by a probe (First Temp Genius Model 3000A Tympanic Thermometer, Sherwood Medical Industries, Ltd, West Sussex) at each visit. The temperature was measured over the temporal portion of the bulbar conjunctiva without anaesthesia. Three measurements were taken and the mean ocular surface temperature at a room temperature of $21^{\circ} \mathrm{C}$. 


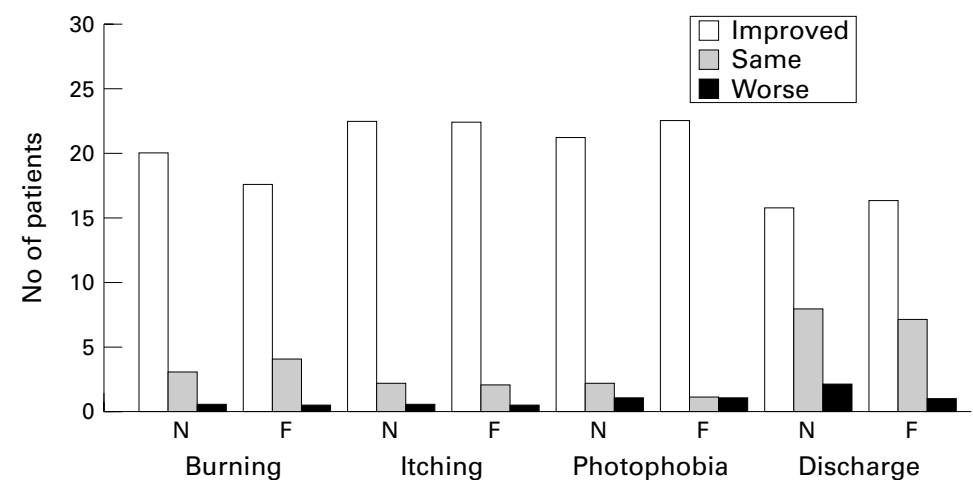

Figure 1 The effects of nedocromil and fluorometholone on the symptoms in patients with vernal keratoconjunctivitis.

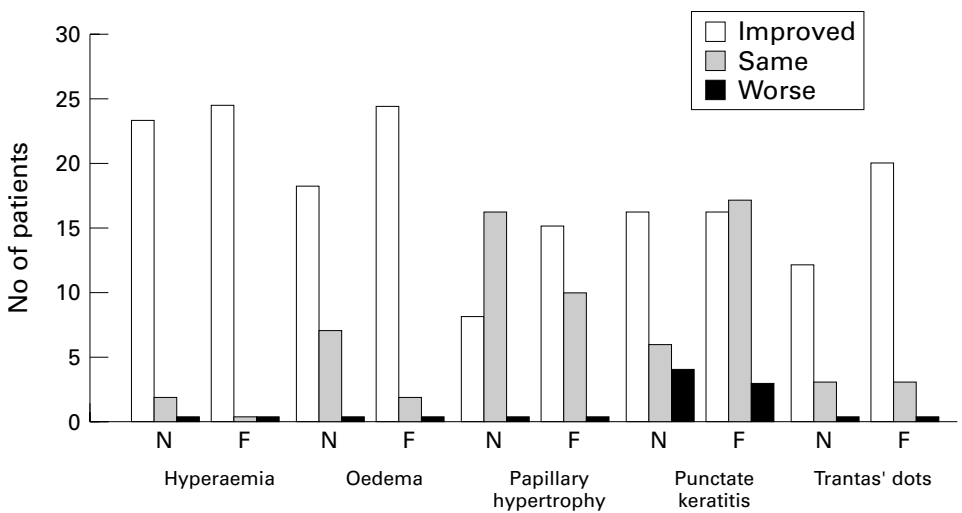

Figure 2 The effects of nedocromil and fluorometholone on the signs in patients with vernal keratoconjunctivitis.
LABORATORY INVESTIGATION

Conjunctival scrapings were obtained from the upper palpebral conjunctiva using a sterile platinum spatula. Scrapings were obtained from each eye at the initial visit (baseline) and at the end of 2 weeks. Samples were transferred to slides, air dried, fixed with methanol, and stained with Giemsa. Eosinophils were counted under oil immersion at $\times 1000$ and the average number per 10 high power fields was recorded.

COMPLIANCE

During the first week of the study, all patients were hospitalised and compliance was controlled by the nursing staff. At each consecutive visit, patients were instructed to bring their medications and the bottles were weighed to ensure adequate medicant consumption. All weights were recorded. All patients showed compliance.

STATISTICAL ANALYSES

The primary efficacy variables were assessed relative to the occurrence of asymptomatic eyes, as appraised by the patient after treatment. This was compared between treatment groups using McNemar test. The changes in variables from baseline after treatment were compared between the two treatment groups using a Wilcoxon matched pairs signed rank test. A binomial test was used to compare the two medications with reference to the patient and investigator's treatment preference.

The proposal was approved by the institution committee on human investigation (ethics committee).

No concurrent medications were allowed during the study. If other medications were required for concurrent illness then the patient was withdrawn from the study. Any adverse event was reported in a separate section. Two patients were excluded because they were taking systemic therapy for asthma.

ASSESSMENT OF VARIABLES

The primary variables of efficacy were the grading of symptoms and the grading of signs which were assessed before initiation of therapy and at the end of the 2 week treatment period. Conjunctival scrapings were obtained at the end of the 2 week period. Secondary variables of efficacy included symptoms reported by the patient and the investigatorassessment of Trantas' dots, superficial punctate keratitis, papillary hypertrophy, eosinophils number in conjunctival scrapings, and the treatment preference (nominated by the patient and by the investigator) at the end of the 2 week treatment period.

\section{MEDICATIONS}

The medications used in the study were masked. Nedocromil sodium $2 \%$ eye drops and fluorometholone $0.1 \%$ eye drops were placed in identical opaque bottles; the bottles had red or blue labels for right or left eyes for identification purposes.

As indicated above, at the end of the 2 week treatment period, each patient crossed over the eye drops for another 2 week course of treatment.

\section{Results}

CLINICAL FINDINGS

All 24 patients who were enrolled completed the study. Out of 24 patients, 16 were asymptomatic and showed no signs or symppatients were asymptomatic in the eye treated with fluorometholone but had symptoms in the eye treated with nedocromil. The difference between the two groups was significant $(\mathrm{p}=$ 0.005). The eight patients who were crossed over showed similar findings to the first treatment period-namely, improvement in the eyes treated with fluorometholone was significantly better than the eyes treated with nedocromil. Figure 1 shows the change in general, the response to treatment was good with fluorometholone had greater improvement in watering and discharge $(p=0.031)$ than those treated with nedocromil. Figure 2 demonstrates the change in conjunctival signs (hyperaemia, oedema, papillary hypertrophy, and punctate keratitis) from baseline. The response to both treatment regimens was good with most patients showing improvement or staying the same.

In both treatment groups, there was a significant decrease in the number of Trantas' dots after treatment. In eyes treated with fluorometholone, there was a greater decrease in the toms in both eyes and the remaining eight symptoms from baseline after treatment. In with both treatment modalities. Eyes treated 
Table 1 Effects of treatment on the change of conjunctival surface temperature $\left({ }^{\circ} \mathrm{C}\right)$

\begin{tabular}{lll}
\hline & $\begin{array}{l}\text { Nedocromil sodium } \\
2 \%\end{array}$ & $\begin{array}{l}\text { Fluorometholone } \\
0.1 \%\end{array}$ \\
\hline Number of patients & 24 & 24 \\
Median & $-1.0^{\circ} \mathrm{C}$ & $-1.2^{\circ} \mathrm{C}$ \\
Range & $+2.8^{\circ} \mathrm{C}$ to $-3.2^{\circ} \mathrm{C}$ & $+2.7^{\circ} \mathrm{C}$ to $-3.5^{\circ} \mathrm{C}$
\end{tabular}

The $\mathrm{p}$ values were determined by the Wilcoxon matched pairs signed rank test $(\mathrm{p}=0.03)$.

Table 2 Treatment preference of therapy for the patient and investigator at the conclusion of the treatment period

\begin{tabular}{lcc}
\hline & \multicolumn{2}{c}{ Treatment preference } \\
\cline { 2 - 3 } & Patient & Investigator \\
\hline No preference & 9 & 6 \\
Nedocromil sodium $2 \%$ & 3 & 5 \\
Fluorometholone $0.1 \%$ & 12 & 13 \\
& $\mathrm{p}=0.018$ & $\mathrm{p}=0.048$ \\
\hline
\end{tabular}

number of Trantas' dots than in eyes treated with nedocromil $(p=0.027)$. In eyes treated with nedocromil, 12 out of 24 showed improvement in the number of Trantas' dots; 12 eyes stayed the same. In eyes treated with fluorometholone, 17 showed improvement in Trantas' dots and seven stayed the same.

\section{CONJUNCTIVAL SCRAPINGS}

The average number of eosinophils per 10 high power fields was recorded before and after therapy. In eyes treated with nedocromil, eight eyes showed a decrease in the average number of eosinophils in conjunctival scrapings while the number of eosinophils decreased in 13 eyes treated with fluorometholone.

OCULAR SURFACE TEMPERATURE

Table 1 shows the change in ocular surface temperature after treatment with nedocromil or fluorometholone at 2 weeks after treatment. The mean decrease in ocular surface temperature was $-1.0^{\circ} \mathrm{C}$ in the nedocromil treated eyes and $-1.2^{\circ} \mathrm{C}$ in the fluorometholone treated eyes. Eyes treated with fluorometholone showed a significant decrease in ocular surface temperature compared with nedocromil treated eyes $(\mathrm{p}=0.03)$.

TREATMENT PREFERENCE

Table 2 shows the overall assessment of the therapy by both the patient and one of the two authors (investigators). The difference in the efficacy assessment (preference of medication) was found to be significant for both the patient $(p=0.004)$ and the investigator $(p=0.01)$ in favour of fluorometholone.

ADVERSE EFFECTS

No adverse effects from the use of nedocromil or fluorometholone were noted in this study.

\section{Discussion}

Vernal keratoconjunctivitis (VKC) is characterised by history of itching, redness, tearing, foreign body sensation, photophobia, and thick mucoid stringy discharge. Patients with VKC present with conjunctival (bulbar/palpebral) limbal and corneal findings. The conjunctival signs consist of hyperaemia, infiltration oedema, papillary hypertrophy, giant papillae, large papillomatous growth, discharge, and Trantas' dots. The limbal signs consist of infiltration of the limbus with tissue hyperplasia, fibrovascular growth, oedema, limbal vascularisation, and Trantas' dots. The corneal findings in VKC may show punctate staining of the cornea with intraepithelial grey-white tiny dots involving part or all of the corneal surface. The corneal epithelium may become devitalised leading to staining with fluorescein. In some patients with VKC, a persistent epithelial defect may develop. The epithelial defect may be singular or multiple, unilateral or bilateral. A corneal plaque may form in the area of the epithelial defect and central corneal scars may occur. Corneal vascularisation may be observed in severe VKC as well as peripheral arcus senilis. Peripheral corneal thinning and irregular astigmatism and keratoconjunctivitis may complicate VKC leading to a decrease in vision. VKC is a severe form of ocular allergy which may result in visual impairment or blindness. The reduction in vision is caused either by the sequelae of the disease itself or as a complication of treatment with topical or periocular corticosteroids.

In a multicentre, double blind group comparative study, sodium cromoglycate $4 \%$ eye drops twice daily over a period of 4 weeks were found to be as effective and well tolerated as $2 \%$ sodium cromoglycate four times daily in the treatment of birch pollen conjunctivitis. Patients treated with topical long term sodium cromoglycate exhibit no adverse reactions and develop no iatrogenic visual loss. However, the combination of sodium cromoglycate with low dose topical corticosteroids may be indicated during exacerbation of severe form of VKC, and in this situation, sodium cromoglycate has a steroid sparing effect. Topical corticosteroids provide symptomatic relief in VKC but once they have been initiated, patients may object to their withdrawal because of the symptomatic relief. In countries where topical corticosteroids are available over the counter, the patient may obtain and use the drug without medical surveillance, and this leads to the sight threatening side effects. This is a serious problem in many developing countries.

Vernal keratoconjunctivitis is a disabling disease of children and young adults. The severity of the disease appears to be greater in warm climates than in cold climates. The majority of cases of VKC develop a spontaneous remission of their disease after puberty. Some patients may persist with a less severe form of the disease in adulthood. Blindness resulting from VKC is rare but long term treatment with topical corticosteroids may lead to glaucoma or cataract and thus to visual loss. It is, therefore, conceded that continuous research for new drugs in the treatment of severe VKC that are safe and effective and steroid sparing, is highly desirable. Most antiallergic medications may be helpful in mild forms of allergic conjunctivitis but have little or no effect in severe VKC. Nedocromil has been shown to be effective in allergic conjunctivitis. ${ }^{17-19}$ Therapeutic options in ocular allergy have been reviewed. ${ }^{23}$ 
In this study, we attempted to evaluate the effects of nedocromil in severe VKC and compared the findings with the effects of fluorometholone in the same patients. VKC has variable clinical manifestations and patients may experience a difference in their manifestations and response to therapy. This study was designed to eliminate some of the bias. Patients were given both treatment regimens, one to each eye. Although patients with severe VKC showed improvement on nedocromil when their symptoms and clinical signs were compared with baseline, fluorometholone appeared to be more effective than nedocromil in ameliorating the signs and symptoms of severe VKC.

The ocular surface temperature showed a decrease in both treatment groups when compared with baseline. Fluorometholone, however, produced a greater decrease in surface temperature than nedocromil. This may be related to the decrease in conjunctival hyperaemia.

The patients and the investigators were consistent in their preference for fluorometholone. Nedocromil 2\% appears to have significant effects in reducing the intensity of allergic symptoms and signs but remained inferior to fluorometholone $0.1 \%$.

The volume of each drop instilled in the conjunctival sac is too small to produce significant systemic absorption of the drug. The concomitant use of both medications may have to be considered. The combined regimen may allow a reduced dosage of fluorometholone with a full dosage of nedocromil.

This study was supported in part by Abdul-Rahman Saad Al-Rashed Fund for Research in Ophthalmology.

The authors have no proprietary interest in any of the drugs or materials used in this study.

1 Tabbara KF, Abu El-Asrar AM. Immunopathogenesis of ocular allergy. In: Oehling AK, Huerta Lopez JG, eds. Progress in allergy and clinical immunology. Seattle: Hogrefe and Huber, 1997;4:381-85.

2 Abu El-Asrar AM, Geboes K, Al-Kharashi S, et al. Adhesion molecules in vernal keratoconjunctivitis. Br F Ophthalmo 1997;81:1099-106.

3 Allansmith MR, Ross RN. Mast cells and the eye. In: Kay $\mathrm{AB}$, ed. Allergy and inflammation. Vol 20. London: Academic Press 1987;307-22.

4 Buckley RJ. Vernal keratoconjunctivitis. Int Ophthalmol Clin 1988;28:303-8.
5 Irani AA, Schechter NM, Craig SS, et al. Two types of human mast cells that have distinct neutral protease compositions. Proc Natl Acad Sci USA 1986;83:4464-8.

6 Church MK. Human mast cell development, heterogeneity and cytokines. In :Oehling AK, Huerta Lopez JG, eds. Progress in allergy and clinical immunology. Seattle: Hogrefe and Huber, 1997;4:95-8.

7 Schwartz LB, Irani AA, Roller K, et al. Quantitation of histamine, tryptase, and chymase in dispersed human $\mathrm{T}$ and TC mast cells. F Immunol 1987; 138:2611-5.

8 Craig SS, Schechter NM, Schwartz LB. Ultrastructural analysis of human $\mathrm{T}$ and $\mathrm{TC}$ mast cells identified by immunoelectronmicroscopy. Lab Invest 1988;59:682-91.

9 Irani AA, Butrus SI, Tabbara KF, et al. Human conjunctival mast cells: distribution of $\mathrm{MC}_{\mathrm{T}}$ and $\mathrm{MC}_{\mathrm{TC}}$ cells in vernal keratoconjunctivitis and giant papillary conjunctivitis. $\mathcal{F}$ Allergy Clin Immunol 1990;86:34-40.

10 Abu El-Asrar AM, Tabbara KF, Geboes K, et al. An immunohistochemical study of topical cyclosporine in vernal keratoconjunctivitis. Am F Ophthalmol 1996;121:156-61.

11 Bleik JH, Tabbara KF. Topical cyclosporine in vernal keratoconjunctivitis. Ophthalmology 1991;98:1679-84.

12 Trocmé SD, Kephart GM, Allansmith MR, et al. Conjunctival deposition of eosinophil granule major basic protein in vernal keratoconjunctivitis and contact-lens associated giant papillary conjunctivitis. Am $\mathcal{f}$ Ophthalmol 1989;108: giant papi.

13 Trocmé SD, Kephart GM, Bourne WM, et al. Eosinophil granule major basic protein deposition in corneal ulcers associated with vernal keratoconjunctivitis. Am f Ophthalmol 1993;115:640-43.

14 Levi-Schaffer F, Rubinchik E. Interleukin-2 modulation of mast cell histamine release is affected by nedocromil sodium. F Allergy Clin Immunol 1993;91:185.

15 Paulmichl M, Norris AA, Rainey DK. Role of chloride channel modulation in the mechanism of action of nedocromil sodium. Int Arch Allergy Immunol 1995;107: 416.

16 Devalia JL, Davies RJ, Befus AD, et al. Inhibitory effects of nedocromil sodium on cytokine production from mast and epithelial cells. Int Arch Allergy Immunol 1995;107:417.

17 Blumenthal M, Cassale T, Doxkhorn R, et al. Efficacy and safety of nedocromil sodium ophthalmic solution in the treatment of seasonal allergic conjunctivitis. Am F Ophthalmol 1992;113:56-63.

18 Jarmoszuk I, Blumenthal M, Silvers W, et al. Nedocromil sodium $2 \%$ ophthalmic solution in the treatment of ragweed seasonal allergic conjunctivitis. f Allergy Clin Immunol 1988;81:174.

19 Leino M, Carlson C, Jaanio E, et al. Double-blind group comparative study of $2 \%$ nedocromil sodium eyedrops with placebo eyedrops in the treatment of seasonal allergic conplacebo eyedrops in the treatment of seaso

20 El Hannawi M. A double-blind controlled group comparative study of ophthalmic sodium cromoglycate and nedocromil in the treatment of vernal keratoconjunctivitis. Br f Ophthalmol 1994;78:365-69.

21 Leino M, Ennevaara K, Latvala AL, et al. Double-blind group comparative study of $2 \%$ nedocromil sodium eyedrops with $2 \%$ sodium cromoglycate and placebo elacebo tis. Clin Exp Allergy 1992;22:929-32.

22 Leino M, Montan P, Njó F. A double-blind group comparative study of ophthalmic sodium cromoglycate $2 \%$ four times daily and $4 \%$ twice daily, in the treatment of seasonal allergic conjunctivitis. Allergy 1994;49:147-51.

23 Hingorani M, Lightman S. Therapeutic options in ocular allergic disease. Drugs 1995;50:208-21. 